\title{
Experiences of running negotiable and non-negotiable developer contributions side-by-side
}

Article

Accepted Version

Wyatt, P. (2017) Experiences of running negotiable and nonnegotiable developer contributions side-by-side. Planning Practice \& Research, 32 (2). pp. 125-170. ISSN 1360-0583 doi: https://doi.org/10.1080/02697459.2016.1222148 Available at https://centaur.reading.ac.uk/66858/

It is advisable to refer to the publisher's version if you intend to cite from the work. See Guidance on citing.

To link to this article DOI: http://dx.doi.org/10.1080/02697459.2016.1222148

Publisher: Taylor and Francis

All outputs in CentAUR are protected by Intellectual Property Rights law, including copyright law. Copyright and IPR is retained by the creators or other copyright holders. Terms and conditions for use of this material are defined in the End User Agreement.

www.reading.ac.uk/centaur 
Central Archive at the University of Reading

Reading's research outputs online 


\title{
Experiences of running negotiable and non-negotiable developer contributions side-by- side
}

\author{
Pete Wyatt \\ Professor of Real Estate Appraisal \\ School of Real Estate \& Planning \\ University of Reading \\ Whiteknights \\ Reading \\ UK \\ p.wyatt@reading.ac.uk
}

\begin{abstract}
In England, Since the 1970s, a system of negotiated project-specific agreements between local planning authorities and developers/landowners has evolved into the sole mechanism by which part of land value uplift 'released' by the grant of planning permission is captured by government. In 2010, in an attempt to simplify and speed up the planning process - negotiated planning agreements were regarded as time-consuming and a brake on development - the Community Infrastructure Levy $(\mathrm{CIL})$ was introduced. Originally intended as a simple flat rate charge to replace site-specific planning agreements, CIL now sits alongside that mechanism so that developers pay CIL to help fund infrastructure provision in the locality, whilst planning agreements help mitigate the impact of their development and provide affordable housing. The experience of running a system of negotiated planning agreements alongside a non-negotiable infrastructure levy offers an opportunity to evaluate these policy shifts in order to assess their strengths and weaknesses and whether there are any wider lessons for international discussions of best practice in land value capture. Drawing on survey findings the paper considers the implementation of $\mathrm{ClL}$ alongside planning agreements, the revenue and expenditure patterns, and the impact of these combined land value capture mechanisms on development activity and, in particular, on affordable housing supply.
\end{abstract}

Key words: Developer, contributions, planning, infrastructure, land 


\section{Introduction}

In the period following the Second World War there were several largely unsuccessful attempts in England to introduce workable betterment taxes. The last of these, the Development Land Tax, was abolished in 1985. Instead, a system of negotiated project-specific agreements between local planning authorities and developers/landowners evolved into the sole mechanism by which part of land value uplift 'released' by the grant of planning permission is captured by government. In addition to cash payments, these planning agreements comprise in-kind contributions towards infrastructure, social housing, educational and community facilities and environmental improvements.

In 2010, in an attempt to simplify and speed up the planning process - negotiated planning agreements were regarded as time-consuming and a brake on development - the Community Infrastructure Levy (CIL) was introduced. Originally intended as a simple flat rate charge to replace planning agreements, CIL now sits alongside that mechanism so that developers pay CIL to help fund infrastructure provision in the locality, whilst planning agreements help mitigate the impact of their development, including the provision of affordable housing.

Over the last five years, for political as well as for administrative reasons, a series of amendments to $\mathrm{CIL}$ and planning agreements have led to what many regard as a complicated set of regulations.

Payment instalment policies, exemptions for small developments and self-build schemes, reliefs for social housing and other exceptional circumstances, restrictions on the pooling of planning obligations, the award of credit for re-using vacant buildings and revenue allocations to neighbourhood groups have been introduced by central government. At the local government level, planning authorities have been adopting more nuanced CIL charging schedules with differential rates depending on land use and location to an extent where, in some cases, CIL is more analogous to a development value tax than an infrastructure levy.

The experience of running a system of negotiated planning agreements alongside a non-negotiable infrastructure levy offers an opportunity to evaluate how these two mechanisms work in practice. The paper is structured as follows. After a literature review that describes the evolution of land value capture policies in England, Section 3 explains the operational characteristics of planning agreements and the infrastructure levy. Section 4 reports the findings of a survey of local authority planning officers, planning consultants and developers that examined experiences of running these two land value capture instruments side-by-side. In particular, it considers how much revenue has been raised and how is it being used, whether developer contributions vary depending on where and when development takes place, the types of development that generate developer contributions and how the amount of developer contributions is assessed. A discussion of the principal issues arising and some concluding comments are provided in Sections 4 and 5.

\section{Literature review}

Because land is scarce and land parcels occupy unique locations (i.e. landowners benefit from monopolistic positions) not all accumulated wealth is the result of landowners' actions. In societies where governments fund the provision of infrastructure, services and amenities, landowners may benefit from land value uplift as a direct result of this publicly funded investment. Furthermore, most countries do not espouse or indeed permit unfettered ownership and exploitation of land, for obvious reasons. Local, national and international environmental and planning laws typically provide a set of rules that govern the way in which landowners may use their land. Chief amongst these rules is the need to obtain planning consent to develop land (including changing its use). In effect, substantial increases in land value can occur upon grant of planning consent. In such circumstances 
the case for a 'betterment' tax is strenghtened. Figure 1 illustrates some examples of measures to tax infrastructure-based and development rights based betterment.

\section{Figure 1 here}

Alterman (2012) offers a more nuanced categorisation of these instruments, splitting them into 'direct' and 'indirect' measures. The direct measures include the capture of unearned increment (e.g. capital gains tax, inheritance tax and transfer tax) and capture of betterment (but specifically land tax or betterment levy type instruments). The indirect measures include developer obligations, planning gain and impact fees. This distinction may not be readily identifiable, indirect measures may be attempts to 'hide' the taxation policy. Alterman (2012) argues that, for indirect betterment capture instruments, the unearned increment rationale remains in the background. She cites planning practice in England, and Planning Circular 05/05 (ODPM, 2005) in particular, that prevented planning obligations from being 'betterment by stealth' and argued that alternative rationales have emerged instead, including the recovery of public investment, provision of public services, internalisation and mitigation of negative externalities for example. Also, what began as indirect instruments may evolve into direct ones. As this paper will discuss, in England, development-specific planning obligations have evolved into methods of land value capture that are now viability tested to ensure the amount captured is economically justifiable.

Attempts to introduce direct betterment capture in England have not been successful. The 1909 Housing Act gave local authorities, when adopting their land use schemes, a "claim to half the amount by which any property is increased in value by the making of the scheme" but the claim was virtually inoperable due to difficulties in exacting the levy from landowners at the time of approval of a land use scheme. Subsequent attempts to introduce national betterment levies, including a Development Charge introduced in 1947, a Betterment Levy in 1967, a Development Gains Tax in 1973 and a Development Land Tax in 1976, have all been repealed. The direct betterment levies failed for a mixture of political and administrative reasons (Oxley, 2006). Politically, UK betterment taxes failed largely because of a lack of credibility over long-term sustainability of the tax. Each attempt at introducing a levy was by a Labour Government and each repeal was by a subsequent Conservative Government and ' $[t]$ here has been a clear incentive to wait for a reversal of the policy before applying for planning permission' (Mirlees, 2011a: 372). The administrative reasons for successive failures of direct betterment levies centre on difficulties associated with establishing the basis for the tax, specifically, valuation complexity.

In England, for the time-being at least and despite a recent and authoritative call for its serious consideration (Mirrlees, 2011b), the death knell has sounded for a nationally imposed betterment levy. However, alternative mechanisms have been evolving at the local level. Mirrlees (2011a) and Alterman (2012) suggest why indirect or locally implemented betterment capture instruments might be preferable to national betterment taxes and levies; they operate under the political radar, have been less transparent, are more directly linked to development activity and its potential negative impact, and are sufficiently flexible to enable adjustment as political and socio-economic circumstances change. Some see the shift from betterment taxation to planning charges as the 'marketisation' of a planning system:

'Planning obligations are probably the most significant element of the planning system where planners are confronted by the need directly to consider (development) economics ... [they] have become a financial and hence a market orientated mechanism through which the social and environmental consequences of development can be determined and their costs met' (Campbell and Henneberry, 2004: 54). 
Initially running alongside the Development Land Tax but later the sole mechanism for land value capture, the Town and Country Planning Act 1971 introduced Section 52 agreements. Renamed Section 106 agreements following enactment of the 1990 Town and Country Planning Act, these agreements enable local planning authorities to enter into legal contracts with developers to regulate aspects of a development as a condition of the grant of planning permission. In the early days, this regulation took the form of site-specific mitigation measures and charges were levied according to formulae for each item. Gradually, some planning authorities began to pool financial contributions from developers into a combined charge per unit of floor area; see, for example, City of London, Thames Gateway Development Corporation, Milton Keynes "infrastructure tariff" (Planning Officers' Society, 2015), a "property tariff" in Swindon and a "strategic tariff" in Ashford (Lord, 2009). Amid concern that these tariff-like charges might not meet Government guidance on the use of planning obligations (Circular 05/05), in 2002-3 the Local Government Department of the then Labour Government considered the introduction of a more formal mechanism, known as an Optional Planning Charge. At the same time (2006), the Treasury recommended the introduction of a tax on planning gain, known as the Planning Gain Supplement. In the face of strong resistance from landowners and developers over its design, and amid concern from local authorities over the role of central government in administering the tax, the Planning Gain Supplement was never implemented and in the 2007 White Paper Planning for a Sustainable Future a locally determined levy was proposed instead. After more consultation, and following enactment of the 2008 Planning Act, the Community Infrastructure Levy (CIL) was introduced in 2010. CIL is a local level, tariff-style approach to capturing some of the land value uplift resulting from the grant of planning permission. Writing before CIL was introduced, Lord (2009) argued that:

'In developing such mechanisms a central aim has been to sever the link between planning obligations and corresponding measures taken to mitigate externalities entailed by site-specific development. Instead, the impulse behind the $\mathrm{CIL}$ is rather to combine multiple developer-contribution-fed funding streams to finance infrastructure projects of regional/national importance.'

CIL was originally intended to replace S106 agreements but that replacement has not happened. Instead, the two mechanisms sit alongside each other so that developers pay CIL to help fund infrastructure provision and pay Section 106 to mitigate the impact of their development, including the provision of affordable housing. Against this background and evolution of land value capture instruments in England, it would seem appropriate to investigate the performance of the current dual mechanisms of S106 planning agreements and CIL. Before doing so, Section 3 describes the research method and provides a more detailed explanation of these two land value capture instruments.

\section{Planning Obligations and Community Infrastructure Levies}

There have been four Government commissioned studies of S106 planning agreements in England over the past decade (Crook et al, 2006, 2008, 2010 and DCLG, 2014). These studies provide estimates of the number and financial value of planning agreements, together with detailed analyses of the type obligations that were agreed and the experiences of negotiating and agreeing them. Building on these four studies, this paper reports the result of a survey undertaken in 2015 of 140 (out of a total of 326) local planning authorities in England. The survey instrument was a targeted questionnaire that was emailed to all 70 local authorities that had adopted a CIL as at March 2015. The survey investigated the attitudes and experiences of implementing and operating CIL and of running $\mathrm{CIL}$ alongside planning agreements. It provided an insight into the way the introduction of $\mathrm{CIL}$ is interacting with the use of planning agreements and how far S106 agreements are being scaled back. The survey also investigated attitudes and experiences of those local authorities that had not adopted a CIL. This sample of 70 'non-adopters' was selected so that it was comparable in terms of 
local authority type and median house price to the 'adopters' sample. The response rate from the $\mathrm{CIL}$ adopters was $67 \%$ and from the non-adopters it was $31 \%$. The overall the response rate from all 140 local authorities was $49 \%$.

The questionnaire survey was supplemented by local authority case studies. These involved interviews with officers from 14 local authorities that had adopted CIL. Case study selection was weighted towards authorities that had been operating $\mathrm{CIL}$ for longest while also providing a reasonable spread in terms of location, type of local authority (district, borough, metropolitan) and real estate values. Interviews lasted between forty minutes and an hour and were conducted using a discussion agenda. Usually the interviews were with the officer responsible for the operation of CIL in the authority. In some cases more than one officer took part in the interview, with the second officer usually involved in policy decisions. The discussion focused on the adoption of CIL, CIL exemptions and reliefs, CIL and S106 in combined operation, collecting and spending payments, handling large-scale developments and the impact on developers and developments, including affordable housing. From these local authority case studies 12 developers were also interviewed, including a mix of national (5), sub-regional (3) and local developers (or their agents) (4). Interviews were undertaken by telephone and lasted about 30 to 45 minutes. The topics mirrored those discussed with the local authority interviewees in order to investigate key issues from what were often opposing viewpoints.

\section{Planning Obligations}

As described in Section 2 above, under Section 106 of the Town and Country Planning Act 1990, applicants and local planning authorities are able to enter into legally binding planning agreements as a condition of the grant of planning permission. These agreements can require or oblige (hence the use of the term 'planning obligations') applicants to undertake or provide a variety of measures including:

- On-site and off-site provision of affordable housing and/or land for affordable housing

- Provision of open space, environmental improvements, ecology, nature conservation, allotments and countryside management

- Provision of sports and community facilities e.g. public toilets, public art, employment and training

- Temporary and permanent highway works, provision or improvement of footpaths and/or cycle routes, traffic and parking management, green transport and travel plans, public transport improvements

- Provision of schools or improvements to schools

- Payments in lieu of the above

Table 1 summarises the main findings of the studies in terms of the number and value of planning obligations agreed in the four financial years examined. The studies span a period of substantial economic upheaval following the 2008 financial crisis so the figures should be viewed in that context. Conservatively speaking, applicants were agreeing to fund approximately $£ 4 \mathrm{bn}$ of planning obligations each year and that around half of this was targeted towards the provision of affordable housing; around 40,000 affordable homes were agreed via planning obligations each year. It should be noted that these figures relate to agreed planning obligations, not necessarily delivered. As Table 2 shows, S106 is an important source of affordable housing supply but completions have been significantly less than agreed provision.

Table 1 here 
The studies revealed that nearly all local authorities have experience of entering into S106 agreements and have an affordable housing policy. Those authorities located in the more prosperous parts of the country have the highest number of agreements, three quarters of which relate to residential schemes. Standard charging has become increasingly common. By 2007-8, nearly all authorities surveyed had adopted a planning obligations policy and most were pooling financial contributions from developers. Changes in real estate prices was regarded the most important factor in explaining changes in the numbers and value of obligations.

Planning agreements, and planning obligations therein, are negotiated on an application-byapplication basis. This means that they enjoy a degree of flexibility and can be tailored to the specific circumstances of the scheme, the site and the market conditions at the time of the planning application. It also means that there can be a relatively direct link between the obligations provided by the applicant and the benefit that they might deliver to the development; a new road or school within a residential scheme for example. Even in circumstances where the applicant is required to provide facilities that they would rather not include due to its potential impact on viability or profitability, such as affordable housing, there is a direct link between obligation and impact. Planning obligations, therefore, can be specifically hypothecated, but this comes at a price. Tailoring obligations to particular schemes, sites and market conditions can be time-consuming and expensive. Valuation advice is often required to ensure the obligations do not render a scheme unviable and legal advice is required to draft the planning agreements. Sometimes the agreements are cloaked in secrecy and there are several high-profile disputes and judicial reviews that have identified this lack of transparency as a serious concern. As a result it became commonplace for local planning authorities to set tariffs or standard charges for planning obligations. These, it is argued, introduce a degree of certainty into the planning obligation estimation process and remove the need for negotiations but, if fixed at too high a level, can cause potential development to be financially unviable, particularly in low value or high cost locations and following market downturns.

\section{Community Infrastructure Levy (CIL)}

CIL provides local authorities in England and Wales with the opportunity to charge developers a fee or levy to help fund infrastructure that is needed as a result of new development. The levy is based on the size and type of the new development. $\mathrm{CIL}$ is intended to operate alongside a scaled back system of section 106 planning obligations, which will only be used for site-specific items and affordable housing. CIL is a local levy and it is the responsibility of planning authorities in England and Wales to decide whether to introduce it.

In setting CIL rates, local authorities are required to strike a balance between deliverability of development plans, desirability of infrastructure and viability of development in their areas ${ }^{1}$. Moreover, scaled-back S106 planning obligations must be necessary to make the development acceptable, directly related to the development, and fairly and reasonably related in scale and kind to the development ${ }^{2}$. Both S106 and CIL are generally required before development starts. The introduction of $\mathrm{CIL}$ as a flat-rate charge for all non-site-specific infrastructure apart from affordable housing makes S106 the only negotiable element of betterment capture and could increase its vulnerability to viability assessments depending on how CIL levels are set.

By the end of August 2015 27\% of local authorities in England had adopted a CIL. Combining these

\footnotetext{
${ }^{1}$ CIL Regulation 14, $2010 \mathrm{CIL}$ Regulations

${ }^{2}$ CIL Regulation 122, 2010 CIL Regulations
} 
authorities with those progressing towards adoption, $58 \%$ of authorities are engaged with CIL. Authorities that have operational CILs are largely concentrated in more affluent parts of the country where property and land values are higher. Table 3 shows that over half of CIL adopters are from London and the south east of England. The two main reasons cited by authorities for not implementing $\mathrm{CIL}$ were lack of land value to support the levy and the prioritisation of affordable housing delivery (which cannot be funded through $\mathrm{CIL}$ ) over infrastructure provision. Figure 2 shows the location of local authorities that have adopted CIL in relation to 2014 residential land values (DCLG, 2015). The relationship between CIL adoption and land value is clear to see.

\section{Table 3 here}

\section{Figure 2 here}

Local authorities that have introduced CIL have adopted a wide variety of charging policies, ranging from flat borough-wide rates to differentiated rates based on geographical zones, scale of development, land use or a mixture of these. Rates vary considerably, with underlying real estate values being the principal determinant (there is a clear relationship between residential charge rates and house prices) but with other key variables, notably the level of affordable housing being sought, having an impact on viability. The majority of authorities have set a CIL rate for residential and retail land uses and around a third have set charges for other uses too. Charges are often differentiated for specific types of residential development (private dwellings, student accommodation, retirement homes, etc.) and retail development (small units, supermarkets, retail warehouses, etc.)

Focusing on $\mathrm{CIL}$ rates for private dwellings, just under a third of local authorities set a single geographical rate, a similar proportion set two zones and the remaining third set three or more. Whilst the average $\mathrm{CIL}$ rate for private residential dwellings across all CIL adopters was $f 95$ per square metre, there was substantial variation in the rates charged within (as well as between) authorities. Charges are highest in London and the surrounding areas in the south east. At the upper end, the majority of charging authorities set maximum residential CIL rates in the $f 50-f 150$ per square metre range. Thirteen authorities have a maximum rate in excess of $£ 200$ per square metre and five of these (all in London) are $£ 400$ per square metre or more. 22 authorities have adopted a single rate for private residential dwellings; ten of which fall within the $£ 51-100$ per square metre range; two are below this level (at $£ 40$ per square metre) and ten are above (from $f 125$ to $f 200$ per square metre).

To compare rates between (rather than within) local authorities an average CIL rate for private residential dwellings was estimated by selecting the middle charging zone (or an average of the middle two in cases where there was an even number of zones). Figure 3 shows the middle residential rate for each local authority family. Authorities in London and Commuter Belt have the highest average residential CIL rates; they are more than double those of Urban England.

Figure 3 here

The average CIL rate for each LPA has been plotted against its median house price in Figure 4 (each point in the diagram representing one local authority). This shows a positive relationship between median house price and CIL charging rate with rates rising steadily as value increases. The figure also shows that there can be significant variation in rates for private residential dwellings between local authorities, even where house prices are broadly similar. There are several possible explanations for this. There may be a very high rate that covers a small geographical area, different proportions of affordable housing might be sought by local authorities in areas of similar values, or 
there might be different levels of anticipated residual S106 payments. Also, there might be different approaches to the viability analysis undertaken by authorities (viability issues are considered in more detail below).

\section{Figure 4 here}

Regarding non-residential land uses, the vast majority (93\%) of CIL charging authorities have set rates for retail development, which attracts some of the highest of any CIL rates. As with residential rates there is diversity in retail rate levels but converging on the $f 50$ to $£ 150$ per square metre range, with the higher end aimed at larger retailers and the lower end at convenience and neighbourhood retail developments. Around a third (32\%) have set rates for other non-residential land uses too and these typically include office developments and leisure facilities. Several authorities have set 'catch all' rates for all other types of development. Some of these are low, for example three have a rate of $£ 5$ per square metre and one has a rate of $£ 10$ per square metre, and some are high, with examples of $£ 75, £ 85$ and $£ 120$ per square metre.

Most of the surveyed local authorities have set a CIL charge for large strategic sites, some at the same rate as for other development and others setting a specific rate for large scale developments. These large schemes (also referred to as 'strategic sites') were perceived to be problematic in terms of CIL charging and there was little consensus as to whether CIL plus scaled-back s106 or conventional s106 planning obligations without any CIL charge would be the better approach. The problem seems to centre on the inflexibility of the CIL chargeable amount as opposed to the negotiated S106. With the latter, the parties can agree interim viability appraisals to change the amount of planning obligations whereas CIL charges can be phased but the amount cannot be varied. One survey respondent commented: "CIL is a more appropriate mechanism for capturing infrastructure funding to mitigate the cumulative impact of smaller scale developments. However it would be more appropriate to have maintained S106 as a mechanism for delivering on-site infrastructure requirements for large-scale sites." Other comments supported this view: "CIL may not work for very big sites where infrastructure requirements are significant" and "Bigger the development the less flexibility with CIL. S106 better for larger sites..."

The average revenue received per CIL charging authority for 2014-15 was $f 0.7 \mathrm{~m}$ from residential developments, $£ 0.2 \mathrm{~m}$ from retail and $£ 0.6 \mathrm{~m}$ from other types of development. In cases where CIL has been in place for two years or more, year-on-year revenue has been increasing significantly from an average of $f 0.2 \mathrm{~m}$ per charging authority in 2012-13, $£ 0.5 \mathrm{~m}$ in 2013-14 to $f 2 \mathrm{~m}$ in 2014-15. This illustrates the time lag between issuing CIL liability notices and receiving revenue.

With regard to CIL expenditure, very few authorities have begun spending on infrastructure at this stage. The local authority interviews revealed that there are still issues, especially for local politicians, surrounding the disconnection between where $\mathrm{CIL}$ is collected and where it is spent. The local authority case studies highlighted widespread acknowledgement that CIL revenue will not be sufficient to fund all the items specified in expenditure schedules. Local authorities are therefore putting in place governance arrangements to identify priorities. Moreover, $\mathrm{ClL}$ revenue will need to be combined with other funding sources to maximise infrastructure delivery. In some instances CIL collected in the early years was less than anticipated, for example: "...make sure people understand that CIL is only one element of the funding available.... CIL is generating less money in early years than anticipated...", "... not enough CIL money to pay (for R123 list priorities) - this is a transitional period but there is a problem..." and "It (CIL money collected) won't cover more than $30 \%$ of costs..."

\section{Running CIL alongside S106}


The CIL charging rates and the amounts of S106 sought from developers is regulated by the use of financial viability assessments, which limit the amount of CIL/S106 to a 'viable' proportion of the land value uplift that flows from the grant of planning permission. In practice, this approach has proved difficult to administer for reasons that centre on the use of these viability assessments, including:

- An absence of evidence on which to base valuations of a development site before and after the grant of planning permission

- Difficulties in agreeing how much of the land value uplift should be allocated to developer obligations under $\mathrm{CIL} / \mathrm{s} 106$

- A lack consensus on how to produce viability assessments that can cope with the dynamics of real estate development

In theory, CIL should have no impact on development viability since it is merely a standardised mechanism for collecting a financial contribution that would otherwise have been collected through S106. The one exception to this rule is small sites (typically less than ten units), which local authorities had tended to exempt from S106 negotiations. The importance of the contribution from all sites, and not just large-scale development, was emphasised by a number of interviewees, either as a reason for an increase in the total S106/CIL contributions or to offset a reduction in the S106 contribution from larger schemes.

Before the introduction of CIL, typical S106 planning obligations included education, libraries and transport measures. These facilities and services are now to be funded through $\mathrm{CIL}$ and, with the exception of affordable housing, any remaining 'scaled-back' S106 requirements are typically limited to 'minor measures', open space and children's play areas. It has proved difficult to source numeric estimates of the scale of the reduction in S106 payments on a per dwelling basis, the few examples given in the survey suggested that $\$ 106$ payments had reduced from around $£ 1,500$ per dwelling to $£ 1,000$ or from $£ 8,000$ per dwelling to $£ 3,000$ with CIL in place. In addition to the reduced level of S106, three interviewees specifically mentioned that the number of S106 agreements had reduced because of the introduction of CIL. None reported an increase. Evidence about payment of S106 preand post-CIL on non-residential schemes is extremely limited but where comment was made it was emphasised that schemes varied so much in character, with many including replacement space, that no clear picture emerges, there are simply 'winners and losers'.

In terms of the total S106 and CIL receipts from pre and post-CIL adoption, there is a mixed picture. Only three authorities were clear that total receipts have increased with CIL in place, three indicated that they think the total receipts will remain about the same, three anticipate decrease and the remainder do not yet have sufficient information to make a judgment. A general finding from the case studies is that there is a dip in the combined S106/CIL contributions immediately post adoption of $\mathrm{CIL}$, compared with the scale of S106 contributions pre adoption. There was no single explanation as to why some authorities are collecting less with CIL in place; reasons put forward included: "In general, the situation might have been better than pre-CIL in terms of contribution levels, especially given [the number] of small developments (in our area) but for the (recent) exemptions..." "Overall seem to be collecting less because are getting a steadier flow of income whereas before, s106 payments arrived in large single payments ... now getting more of a trickle..."

The developer case studies provided a very different view on the scale of payments requested by local authorities before and after the adoption of CIL. Of the nine developers who expressed a view, six stated that payments had increased post CIL with phrases such as 'massively' and 'increased 
substantially' being used. Three specific examples were given of the level of increase in costs: from $£ 3,000$ per dwelling pre CIL to $f 10,000$ with CIL and scaled-back s106 in place; another that payments had 'doubled'; and another that payments had increased by 'between 5 and 10 times'. For the other three developers, the general view was that there had been no overall change in the level of payments and/or that it is difficult to tell, as no two sites are the same.

Respondents to the survey had differing views about how scaled-back s106 payments and CIL were operating together. Just over half (25) of surveyed CIL adopters felt that planning obligations are now simpler and quicker to agree post CIL. 16 felt that they were not and two thought that it was too early to tell. Many comments reflected the ease and speed of the CIL process, particularly when compared to previous s106 negotiations. One respondent commented that the process is "Easier to administer and seek outstanding contributions from developers." Another stated, "We have found the process generally to be a lot simpler than the regulations suggest." One respondent noted that the quantity of s106 agreements had fallen dramatically following the introduction of CIL: "We have seen approx. 90\% reduction in s106 agreements." One of the responses received gave some indication as to why the procedure was more straightforward post-CIL: "There are fewer heads of terms the developer has to enter into ... S106 obligations ... tend to be standard and require less negotiation... There is a lot more consistency as the [authority] endeavours work with a template agreement and make amendments only when necessary." Another respondent concurred: "There is now less complexity, as only a limited number of s106 agreements are now required, chiefly for affordable housing." Other, usually scheme-specific, types of S106 contributions were being sought, including play equipment, open space, and some transport measures but the number of these was relatively low and no clear pattern emerged.

Many of the case study local authorities echoed the positive views of CIL with half seeing the combined process of charging CIL and negotiating scaled-back s106 requirements as a simpler process. For the case study authorities, as in the questionnaire survey, this is largely explained by the reduction in the number of s106 requirements to negotiate, for example: "overall is less onerous and saves time", "It [introduction of CIL] has resolved these arguments. For specific sites its (i.e. negotiation re s106) not necessarily disappeared ... but we can focus on key mitigation elements of schemes - it's a positive" and "S106 contributions secured through negotiations usually works quite well..."

However, not all CIL adopters held these positive views. Three respondents felt that the process of obtaining planning obligations had not improved, mainly because of the procedures required in applying CIL: "For those applications that smoothly move through each of the intended stages of the CIL process, the amount of additional administration and documentation is minimal. However, a significant proportion requires extensive additional correspondence i.e. requesting documents, explaining procedures, notifying liable parties of surcharges/legal action, responding to complaints, etc." Other comments (made by seven respondents) indicated the complexity that remains when negotiating site-specific s106 planning obligations. Three case study authorities considered that the introduction of CIL had made s106 negotiations more complex, particularly in the case of larger sites.

Developers (from the developer case studies) generally felt the process of negotiating s106 agreements with $\mathrm{CIL}$ in place was no different from the situation pre-CIL. For example: "One would hope that a benefit of CIL is speed. It takes a long time to get planning permission factor in a year for planning. Substantial time taken in discussing and negotiating S106 and getting document agreed. This has not changed even if just includes affordable housing." Similarly, "Preferred the old system - thought CIL would streamline s106 process and thought this was a good idea but still require s106 charges so end up with CIL and s106. No change in the amount of time negotiating s106..." Only one out of the 12 developers interviewed thought that the process was 
now easier "...as you know what you have to pay".

One of the key differences between CIL and planning obligations that was highlighted in the interviews was that $\mathrm{CIL}$ is a fixed levy and S106 is negotiable. This has led to concerns that, where scheme viability is an issue, there will be a reduction in planning obligations sought and, notably, a reduction in affordable housing provided. Negotiating affordable housing contributions remains central to the process of agreeing scaled-back planning contributions as these comments from the questionnaire survey demonstrate: "The council has scaled back its planning obligation requirements since adoption of CIL. However, affordable housing was already the most difficult S106 item to negotiate, and this remains the case." In addition, "Site-specific needs have not changed; in addition the question of viability of affordable housing is now raised more frequently."

However, the questionnaire survey of CIL adopters showed that only three authorities felt that the introduction of $\mathrm{CIL}$ had affected the delivery of affordable housing, with one stated " $\mathrm{CIL}$ was delivered alongside a review of the Local Plan including the affordable housing targets. In a number of locations the proportion of affordable housing sought reduced in order to achieve the necessary infrastructure investment" and another that "...on a few marginal schemes a reduction in affordable housing provision has been accepted when accompanied by an appropriate viability assessment, however this was the same under the $\$ 106$ regime." On the other hand, 33 authorities felt that CIL had not had an impact on the delivery of affordable housing. Other authorities felt that it was too soon to tell. Turning to the 14 case study authorities, only two commented that the introduction of $\mathrm{CIL}$ had had a direct impact on the delivery of affordable housing. In one case, this had affected the tenure mix of the affordable housing achieved (although the overall percentage had held up) and the other authority had been achieving a lower percentage post CIL. Half of the case studies said that there had been no change (or only a minor decrease) and the others either did not know or felt that it was too early to tell. In one case, a downturn in delivery of affordable housing was attributed to the then national site size threshold for affordable housing of ten dwellings. Another respondent commented that there are "Difficulties with or without CIL, it is resisted regardless." Changing market conditions were also identified by some interviewees with two mentioning that "improving market conditions' had overcome any detrimental impact that CIL might have on viability. Another interviewee commented that affordable housing delivery had been declining prior to the introduction of CIL and its continuing decline post-CIL was part of this wider trend.

\section{Discussion}

\section{$\underline{\text { Administration }}$}

Local authorities generally felt that CIL was relatively straightforward to administer, the process is transparent and charging is clear and predictable. CIL rate setting, charging and spending are all administered at the local level. Whilst this devolved mechanism empowers decentralised decisionmaking, what results is a patchwork tax. Decisions about whether to charge or not, what rates to charge and types and locations of development activity should be liable are made on an authorityby-authority basis. Once a local authority has adopted CIL, the levy is non-negotiable. The CIL rate or rates are fixed at the local level and can vary between localities and land uses. It is only possible to alter these rates when CIL is periodically reviewed, perhaps to bring them into line with market values. Planning obligations, on the other hand, are negotiated on a scheme-by-scheme basis but in the context of adopted planning policies where they exist, including targets for affordable housing. This dual approach seems to be at odds with the views of some commentators. For example, the DCLG (2007) regarded individually negotiated S106 agreements as "an effective device but not a very efficient one", and Ball (2010) recommended that "Once CIL is introduced, it would seem sensible to fix S106 levels in the same way and preferably simultaneously; rather than to have two divergent 
approaches, one of which is subject to length and costly negotiation and contentious requirements." Most local authorities have scaled back S106 planning agreements to encompass affordable housing and site-specific infrastructure requirements.

There have been a number of amendments to the original CIL regulations, including several exemptions and reliefs from the levy such as exemption for small sites, self-build developments, residential annexes and extensions, and vacant building credit. These have undermined any anticipated consistency in CIL charging regimes. Perhaps the most concerning implication of local rate setting for CIL is the spatial inequality of revenue potential. Authorities in the affluent parts of the country, and in London and the south east of England in particular, are able to charge CIL at levels that should contribute significantly towards infrastructure funding. Whereas it is unlikely that authorities in less affluent areas will be able to raise sufficient revenue from CIL to contribute meaningfully towards infrastructure investment. The result will be a widening gap between these two groups of authorities and a growing disparity between infrastructure investments.

\section{Viability}

A key aspect of betterment taxation, whether direct or indirect, is getting the amount of land value capture right - a balance between revenue raising potential and maintaining supply of development land. This is a particular issue for countries with privatised ownership of land. Since the tax is eventdriven rather than recurrant, if taxpayers (landowners) feel that the tax is too high they can 'opt' not pay the tax by not developing their land, thus restricting the supply of new land for commercial and residential development. This balance between maximising betterment (although not referred to as such by the UK Government) and maintaining developmnent land supply has been the focus of planning policy in England over recent years. Policy now dictates that the amount of CIL/S106 payment must not compromise the financial viability of a proposed development, but determining when viability is compromised by the amount of payment has proved problematic to say the least. Development viability appraisal has emerged as a method of assessment of the financial impact of planning payments on development viability. A range of appraisal models has been applied but all are founded upon a 'residual' approach to valuing land; a method that has long been criticised by the various professions that have had to use it (Coleman et al. 2012). Nevertheless, these appraisal models now play a central role in local planning authorities' policy formation regarding targets for planning obligation payments and, at a project scale, are the nexus for negotiations and arbitration between developers, landowners and planners (McAllister et al, 2015).

UK Government policy requires S106 planning obligations and CIL to be tested for economic viability in forward planning documents, documents that remain in force for significant periods of time and often over market cycles. Consequently, planning obligations are largely a fixed cost; 'largely' because, although a CIL is set, S106 costs can be negotiated on a site-by-site basis. So planning obligations are charged on a geared surplus or residual sum, and the charging is done on an areawide basis over market cycles. As a result $\mathrm{CIL}$ rates have tended to be quite low and planning obligations remain as the 'flex' to be negotiated at the time a planning application is submitted. This means that opportunities to obtain higher amounts of levy or obligation from more profitable sites are lost. Alterman (2012) suggests that governments should have well trained professionals to negotiate with developers or to develop preset formulae of impact assessment. The professionals need to be knowledgeable in real estate economics to be able to assess the limits of how much may be exacted from the developer without "killing" the projects. Local government should monitor land prices in order to be able to challenge developers' arguments that the exactions in fact raise the cost of housing or other products. There should be enough transparency in negotiated exactions to help withstand legal challenges (yet full disclosure is often not possible in order to protect the legitimate economic interests of the developers). 


\section{Revenue and expenditure}

With regard to revenue, CIL seems to work best in urban areas where there is plenty of development taking place. Set at a low rate and for many types of development, $\mathrm{CIL}$ is capable of generating a regular flow of infrastructure revenue. It also has the advantage of being able to be dedicated to large citywide infrastructure projects such as light rail, trams or other similar infrastructure. However, it would appear from the investigations undertaken as part of this research that CIL is not performing in the way that was originally intended. Fundamentally, there would appear to be a substantial shortfall between revenue and planned expenditure. Although opinion varied, the consensus at this early stage of CIL implementation was that there had not been a negative effect on affordable housing supply.

A widely held view amongst developers was that there is no direct link between the CIL revenue that a development generates and the infrastructure that it is used to fund. Moreover, most developers felt that level of contributions had increased after the introduction of CIL, whereas local authority opinion was more divided. Regarding the amount of levy (as a proportion of land value uplift), there are concerns over the cumulative impact of multiple land value capture mechanisms and priority of charge. Because CIL and S106 are administered separately, landowners and developers feel as though they are 'paying twice' for infrastructure. In London, there is a GLA CIL, borough-wide CILs and S106. CIL takes priority over S106 (and within S106, scheme mitigation measures take priority) so if viability is marginal then community benefits such as affordable housing are most at risk from lack of funding.

Turning to the flexibility of S106 and CIL, specifically in terms of review and adjustment of rates (for market, political reasons), it is important to maintain some consistency and longevity of policy in land value capture because uncertainty encourages landowners to exercise their option to defer sale. S106 policy targets are unable to respond timely to market dynamics. In addition, it is difficult to cyclically adjust CIL. Consequently, rates kept low. The problem centres on a static viability model that is applied through time: fixed amounts of planning obligations mean that landowners receive excessive prices in an upturn relative to planning obligations and insufficient return in a downturn. Various compromises have been introduced including site-by-site negotiations, low, dynamic targets and differential targets for various types of change of use and locations. It is questionable whether these measures provide a robust, equitable split of land value uplift.

It is too early to identify examples of spending but both S106 and CIL do offer clarity over expenditure items. S106 benefits from a close association between revenue collection and expenditure in terms of location and timescale whereas CIL does not, but the scaling back of S106 means that scheme-specific expenditure has been compromised. CIL does not facilitate redistribution of revenue to local authority areas that are unable to raise sufficient revenue themselves. As Alterman (2012) points out, these instruments are often applied case by case without ensuring equality among landowners, are open to political and legal challenges regarding bias and favouritism, revenue often unpredictable as it is dependent on economy/market and negotiation and the amount of revenue may only be small proportion of unearned increment.

\section{Conclusions}

Tariff-style CIL provides up-front revenue, a relatively predictable revenue stream (at least more predictable than S106) due to the set fees and schedule of liable developments and, via annual reporting, a more transparent breakdown of revenue and expenditure over time. CIL has been levied on a wider spectrum of development sizes and types than S106 (although diminished because of 
exemptions). Local authorities in England have found, though, that CIL requires high set-up costs and on-going administration is time-consuming and costly, particularly if regular reviews are anticipated. A flat rate, up-front levy seems to be less appropriate for large development schemes constructed over long periods of time, particularly phased housing schemes. There is a question mark over whether many local authority CILs will generate sufficient revenue to fund the infrastructure spending requirements set out in CIL charging schedules. Relatedly, developers seem unhappy with the disconnection between revenue collection on the one hand and delivery of infrastructure on the other, which may be temporally and geographically remote from the scheme that generated the funding.

\section{Acknowledgements}

This work was supported by the UK Department for Communities and Local Government under Project Number CPD/004/109/058.

\section{References}

Alterman, R. (2012) Land use regulations and property values: The "Windfalls Capture" Idea Revisited, Pre-publication version of: Chapter 33, pp. 755-786 in: The Oxford Handbook on Urban Economics and Planning, Edited by Nancy Brooks, Kieran Donanghy and Gerrit-Jan Knapp, Oxford University Press

Ball, M. (2010) The housebuilding industry: promoting recovery in housing supply, Department for Communities and Local Government

Brownill, S., Cho, Y., Keivani, R., Nase, I., Downing, L., Valler, D., Whitehouse, N. and Bernstock, P. (2015) Rethinking planning obligations: balancing housing numbers and affordability, Joseph Rowntree Foundation

Campbell, H. and Henneberry, J. (2005) 'Planning obligations, the market orientation of planning and planning professionalism', Journal of Property Research, 22(1), 37-59

Coleman, C., Crosby, N., McAllister, P. and Wyatt, P. (2012) Development Appraisal in Practice: Some Evidence from the UK Planning System, Journal of Property Research, 30(2), 144-165

Crook, A., Henneberry, J., Rowley, S. and Watkins, C. with the Halcrow Group (2006), Valuing Planning Obligations in England, London, Communities \& Local Government. http://webarchive.nationalarchives.gov.uk/20120919132719/http://www.communities.gov.uk/a rchived/publications/planningandbuilding/valuing-planning

Crook, A., Henneberry, J., Rowley, S., Smith, R., \& Watkins, C. (2008), Valuing Planning Obligations in England; Update Study for 2005-06, London, Communities \& Local Government. http://webarchive.nationalarchives.gov.uk/20120919132719/http://www.communities.gov.uk/d ocuments/planningandbuilding/pdf/obligationsupdatestudy.pdf

Crook, A., Dunning, R., Ferrari, E., Henneberry, J., Rowley, S., Watkins, C., Burgess, G., Lyall-Grant, F., Monk, S., \& Whitehead, C. (2010), The Incidence, Value and Delivery of Planning Obligations in England in 2007-08, London, Communities \& Local Government. http://www.cchpr.landecon.cam.ac.uk/Downloads/VPO3\%20final\%20report.pdf

DCLG (2007) The Callcutt review of housebuilding delivery, Department for Communities and Local Government

DCLG (2012) Community Infrastructure Levy Guidance, Department for Communities and Local Government, December

DCLG (2014) Section 106 Planning Obligations in England, 2011-12: Report of study, Department for Communities and Local Government, London

DCLG (2015) Land value estimates for policy appraisal, Department for Communities and Local Government

DCLG (2015b) Community Infrastructure Levy Review Panel Questionnaire, Department for 
Communities and Local Government

HM Treasury (2004) Barker Review of Housing Supply - 'Delivering stability: securing our future housing needs' http://webarchive.nationalarchives.gov.uk/+/http://www.hmtreasury.gov.uk/consultations and legislation/barker/consult barker index.cfm

Lord, A. (2009) The Community Infrastructure Levy: An Information Economics Approach to Understanding Infrastructure Provision under England's Reformed Spatial Planning System, Planning Theory \& Practice, 10(3), 333-349

McAllister, P., Street, E. and Wyatt, P. (2015) Governing calculative practices: an investigation of development viability modelling in the English planning system, Urban Studies, DOI: 10.1177/0042098015589722

Mirrlees, J., Adam, S., Besley, T., Blundell, R., Bond, S., Chote, R., Gammie, M., Johnson, P., Myles, G., Poterba, J. (2011a) Tax by design, http://www.ifs.org.uk/docs/taxbydesign.pdf

Mirrlees, J., Adam, S., Besley, T., Blundell, R., Bond, S., Chote, R., Gammie, M., Johnson, P., Myles, G., Poterba, J. (2011b) The Mirrlees Review: Conclusions and Recommendations for Reform, Fiscal Studies, 32(3), 331-359

ODPM (2005) Planning Obligations Circular 05/2005, Office of the Deputy Prime Minister, London

Oxley, M. (2006) The Gain from the Planning-Gain Supplement: A Consideration of the Proposal for a New Tax to Boost Housing Supply in the UK, International Journal of Housing Policy, 6(1), 101-113

Planning Officers' Society (2015) Planning for a better future: our planning manifesto for the next government 


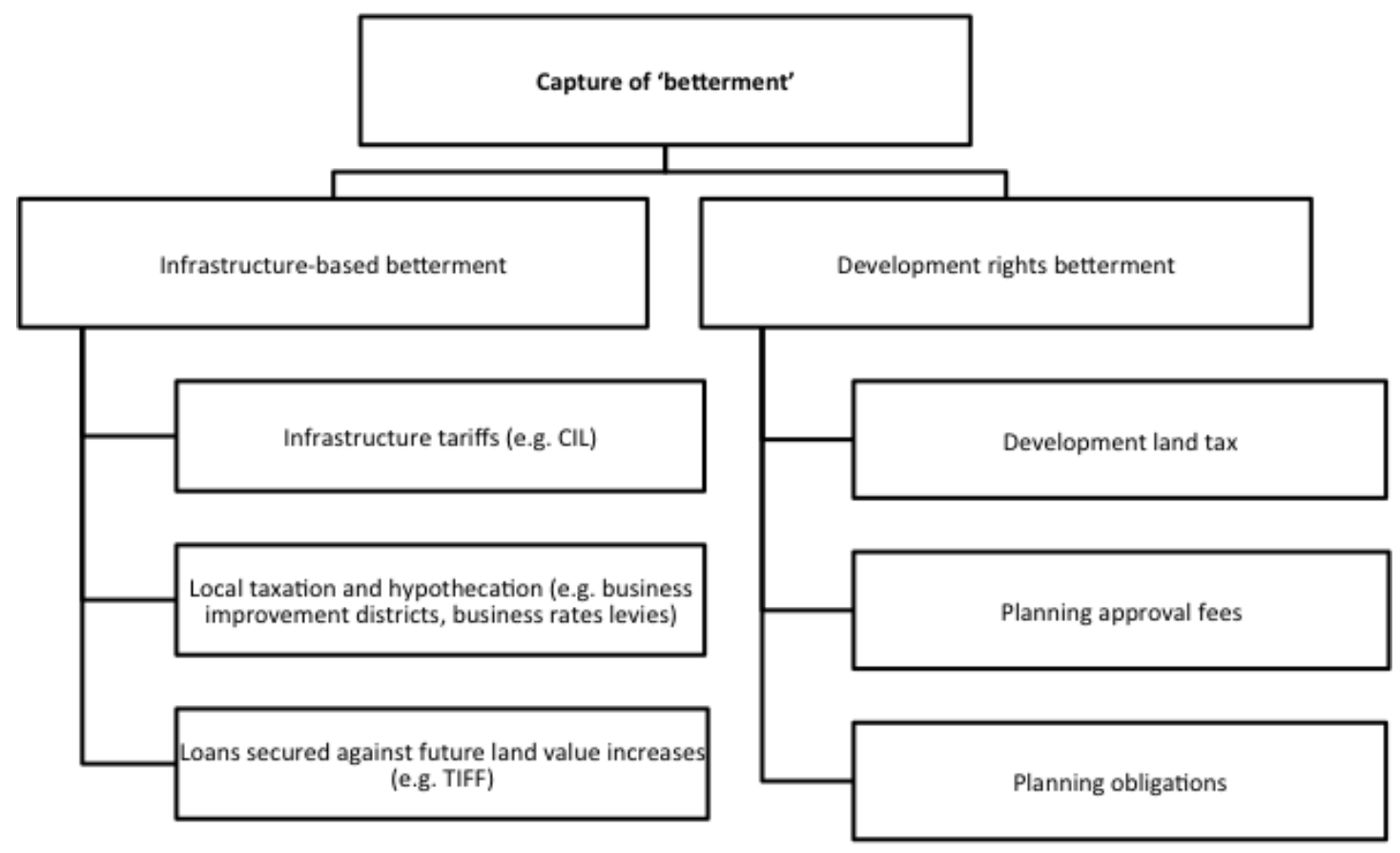

Figure 1: Betterment taxation instruments 


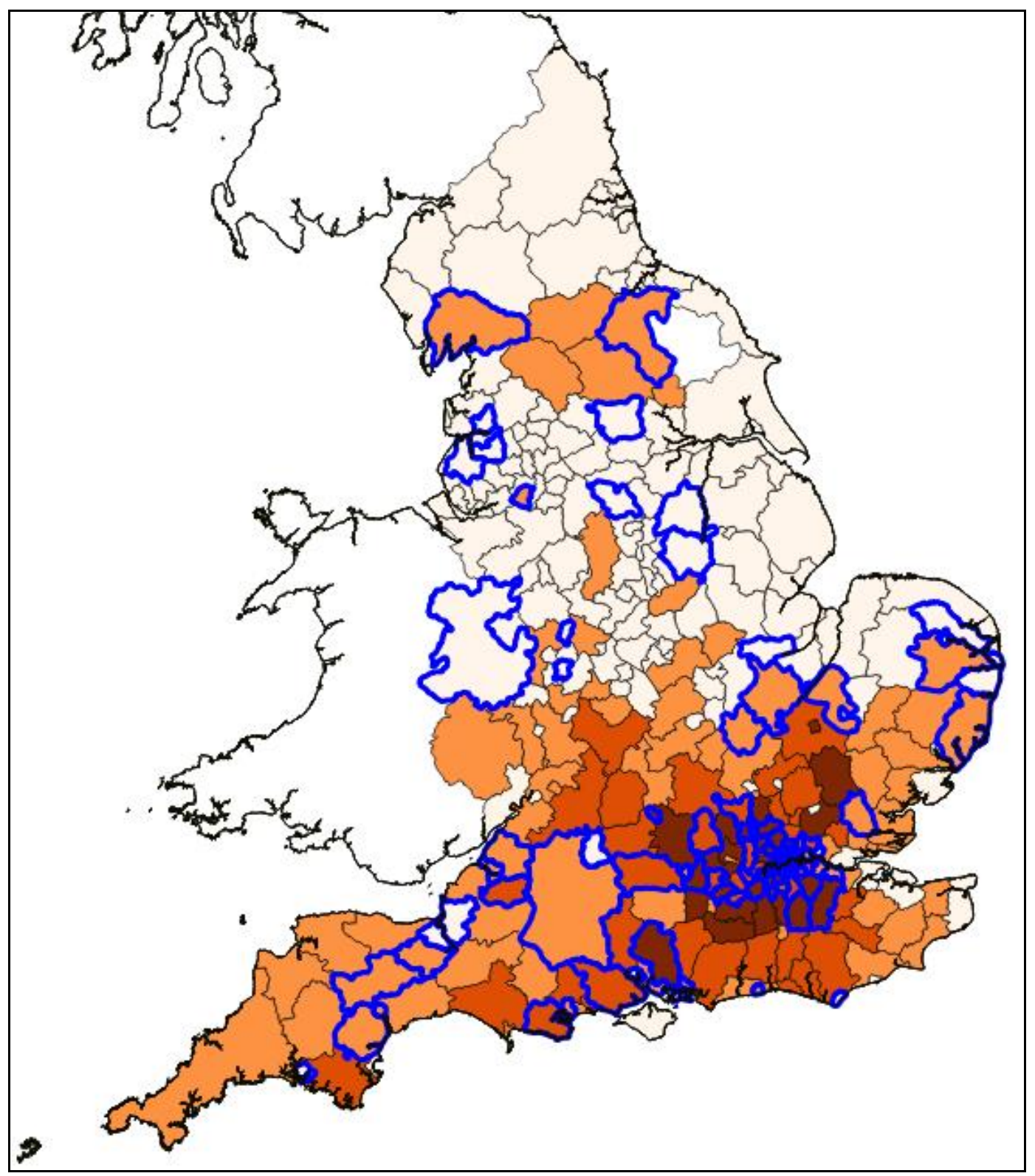

Source of data: DCLG (2015) Land value estimates for policy appraisal

Figure 2: CIL adopters in England as at March 2015 (outlined in blue) overlaying 2014 land value estimates (darker shades represents higher land values) 


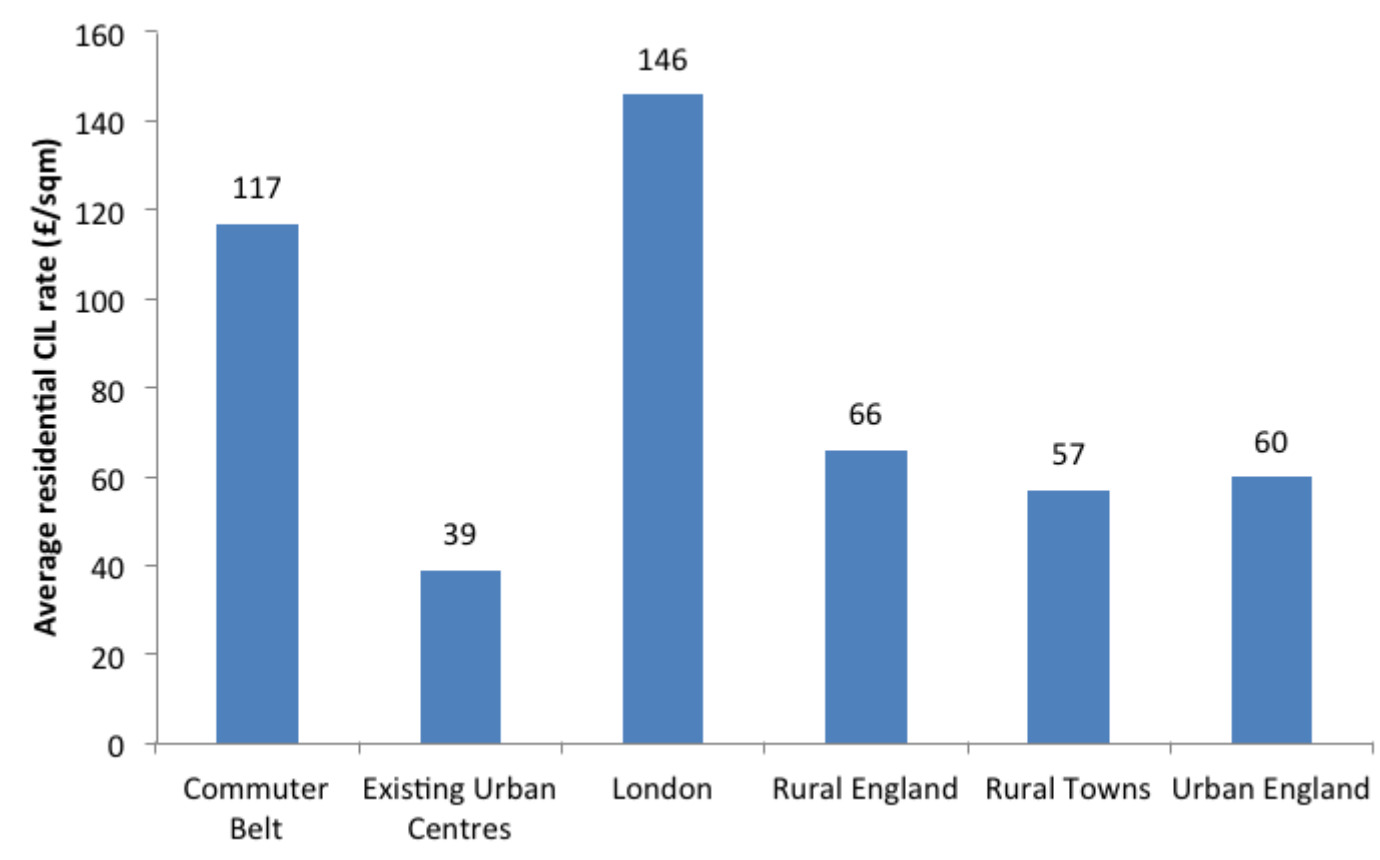

Figure 3: Average residential CIL rate by local authority family

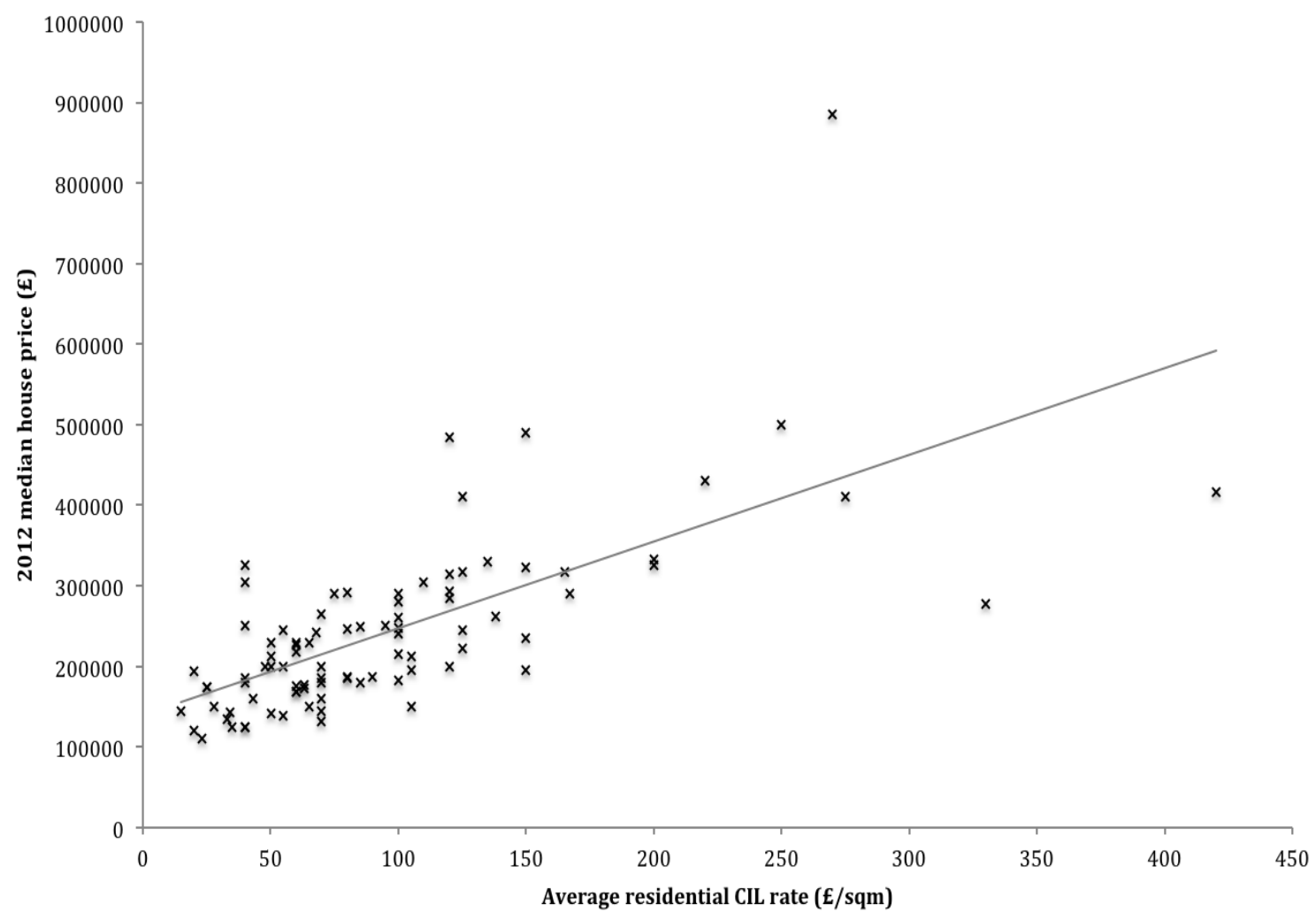

Figure 4: Median house price and average residential CIL rate for each local authority 
Table 1: Planning obligations agreed

\begin{tabular}{|c|c|c|c|c|}
\hline $\begin{array}{r}\text { Year of survey: } \\
\text { (financial year to which each survey relates): }\end{array}$ & $\begin{array}{c}2006 \\
(2003 / 04)\end{array}$ & $\begin{array}{c}2008 \\
(2005 / 06)\end{array}$ & $\begin{array}{c}2010 \\
(2007 / 08)\end{array}$ & $\begin{array}{c}2014 \\
(2011 / 12)\end{array}$ \\
\hline $\begin{array}{l}\text { Average number of planning agreements per } \\
\text { local authority }\end{array}$ & 25 & 25 & 30 & 20 \\
\hline Number of affordable homes & 31,500 & 44,400 & 48,000 & 32,000 \\
\hline $\begin{array}{l}\text { Estimated value of affordable housing } \\
\text { obligations }\end{array}$ & $f 1.2 \mathrm{bn}$ & $f 2 b n$ & $f 2.6 \mathrm{bn}$ & $f 2.3 \mathrm{bn}$ \\
\hline $\begin{array}{l}\text { Estimated value of planning obligations, } \\
\text { excluding affordable housing }\end{array}$ & $£ 0.7 \mathrm{bn}$ & f2bn & $f 2.2 \mathrm{bn}$ & f1.4bn \\
\hline Estimated total value of planning obligations & f1.9bn & f4.0bn & $f 4.8 \mathrm{bn}$ & f3.7bn \\
\hline
\end{tabular}

Note: values are nominal figures

Table 2: Affordable homes completed through S106

\begin{tabular}{|l|c|}
\hline $1999 / 00$ & 9,200 \\
\hline $2000 / 01$ & 9,300 \\
\hline $2001 / 02$ & 10,300 \\
\hline $2002 / 03$ & 12,600 \\
\hline $2003 / 04$ & 16,400 \\
\hline $2004 / 05$ & 18,200 \\
\hline $2005 / 06$ & 23,900 \\
\hline $2006 / 07$ & 25,800 \\
\hline $2007 / 08$ & 27,300 \\
\hline $2008 / 09$ & 32,300 \\
\hline $2009 / 10$ & 29,100 \\
\hline $2010 / 11$ & 29,000 \\
\hline $2011 / 12$ & 17,000 \\
\hline $2012 / 13$ & 15,600 \\
\hline $2013 / 14$ & 16,200 \\
\hline
\end{tabular}

Source: Whitehead (2007) and Brownill et al (2015)

Table 3: Number of local authorities that have adopted CIL

\begin{tabular}{|c|c|c|}
\hline \multirow{5}{*}{ 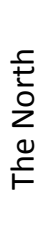 } & North East & 0 \\
\hline & North West & 6 \\
\hline & Yorkshire \& Humber & 3 \\
\hline & East Midlands & 2 \\
\hline & West Midlands & 3 \\
\hline \multirow{4}{*}{ 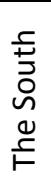 } & East of England & 14 \\
\hline & London & 27 \\
\hline & South East & 22 \\
\hline & South West & 13 \\
\hline
\end{tabular}

